\title{
Uma abordagem de Mineração de Dados Educacionais para previsão de desempenho a partir de padrões comportamentais de Autorregulação da Aprendizagem
}

\author{
Rodrigo Lins Rodrigues (autor) ${ }^{1}$, Paulo Jorge Leitão Adeodato (co-orientador) ${ }^{2}$, \\ Alex S. Gomes (orientador) ${ }^{2}$ \\ ${ }^{1}$ Universidade Federal Rural de Pernambuco - UFRPE \\ Recife - Brasil \\ ${ }^{2}$ Universidade Federal de Pernambuco - UFPE \\ Recife - Brasil \\ rodrigo.linsrodrigues@ufrpe.br, $\{a s g, j l a\} @ c i n . u f p e . b r$
}

\section{Resumo:}

O presente estudo buscou desenvolver um processo de modelagem preditiva do desempenho de estudantes por meio de indicadores comportamentais de autorregulação da aprendizagem em ambientes de LMS. A abordagem foi realizada por meio da mineração de dados contidos em um ambiente de aprendizagem do tipo LMS de uma instituição de ensino superior. A metodologia foi desenvolvida em seis fases: entendimento do domínio em educação, entendimento dos dados educacionais, preparação dos dados para EDM, modelagem, avaliação do modelo e implementação da solução educacional. Os dados utilizados na fase de modelagem foram armazenados no LMS Moodle durante um período de sete anos. Na fase de modelagem foi realizado o desenvolvimento, avaliação e comparativo entre quatro modelos de previsão, por meio dos algoritmos de Árvore de Decisão (CART), Regressão Logística, SVM e Naive Bayes. O modelo de regressão logística apresentou-se como sendo o mais satisfatório para predizer o desempenho acadêmico dos estudantes, sendo capaz de fazê-lo com uma taxa de acurácia de 0,893 e área sobre a curva ROC de 0,9574. Como forma de materializar o conhecimento adquirido na fase de mineração dos dados, especificamente na modelagem do classificador de desempenho. Projetamos uma interface de dashboard que buscou aumentar a capacidade de professores e tutores em perceber o desempenho de alunos a partir do seu registro comportamental. Uma vez que este trabalho desenvolveu e avaliou uma solução de software com propósitos de utilização no contexto da educação a distância, sua evolução e validação em contextos reais torna-se uma essencial. Além disso, com base neste trabalho, outros pesquisadores poderão se concentrar na aplicabilidade da solução para turmas reais e verificar sua robustez e por consequência a geração de novos requisitos, por meio de experimentos de maior duração e com outras instituições de ensino.

Referência: RODRIGUES, RODRIGO; GOMES, A. S. Previsão de desempenho de alunos baseados em construtos de autorregulação da aprendizagem. In: Congresso Brasileiro de Informática na Educação, 2017, Recife. $28^{\circ}$ Simpósio Brasileiro de Informática na Educação, 2017. 